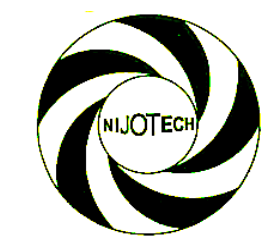

Nigerian Journal of Technology (NIJOTECH)

Vol. 36, No. 2, April 2017, pp. $403-410$

Copyright@ Faculty of Engineering, University of Nigeria, Nsukka,

Print ISSN: 0331-8443, Electronic ISSN: 2467-8821

www.nijotech.com

\title{
PERFORMANCE OF CONCRETE WITH PARTIAL REPLACEMENT OF FINE AGGREGATES WITH CRUSHED WASTE GLASS
}

\author{
A. W. Otunyo ${ }^{1,}{ }^{*}$ and B. N. Okechukwu ${ }^{2}$ \\ 1,2 DePt. of Civil Engr., Rivers State Univ. of SCi. \& TeCh. NKPolu Port HARCourt, Rivers STATe, NigERIA. \\ E-mail addresses: ${ }^{1}$ umutuigili@yahoo.com, 2nwaewo.okechukwu@gmail.com
}

\begin{abstract}
Aggregate, both fine and coarse are major components of concrete. The cost of these aggregates is on the increase. There is also a serious environmental concern for the disposal of waste glass world-wide. These factors are major thrusts of this study- the investigation of crushed waste glass as partial replacement of fine aggregate in concrete, with a view to protecting the environment and also reducing the cost of concrete. The study investigated the level of replacement of fine aggregate with waste glass that will result in optimal compressive strength. A total of 36 cubes were cast. 6 cubes without waste glass (control) and 30 cubes containing waste glass as partial replacement for fine aggregates at 15\%, 25\%, 35\%, $45 \%$, and $50 \%$. Water/cement ratio of 0.6 was used. The concrete cube samples were cured and tested at 7 and 28 days respectively for compressive and flexural strength, water absorption and light weight character. Compressive strength were found to increase by 3\% and 7\% at 7 and 28 days respectively as waste glass content was increased up to $15 \%$ replacement level, after which the compressive strength started to decrease. Flexural strength remained constant between the control value and 15\% replacement level, after which it started to fluctuate, (decreasing by $25 \%$ and $47 \%$ at $25 \%$ replacement level at 7 and 28 days, and experienced an increase of 33\% and 37.5\% at $35 \%$ at replacement level. Water absorption of the concrete decreased as the waste glass content increased. Initial and final setting times decreased as the waste glass content increased, while the workability of the concrete increased as the waste glass content increased and started to experience a decrease at $35 \%$ waste glass replacement level.
\end{abstract}

Key Words: compressive strength, concrete, crushed waste glass, flexural strength, setting time, water absorption and workability.

\section{INTRODUCTION}

Concrete is generally composed of aggregates, cement and water. Cement is hydrated to form a gel around aggregates, which sets thus binding the concrete mass. The aggregates should have good mechanical properties in terms of shape, density, grading, hardness and purity to achieve the required strength and durability. The fine aggregate is usually, sand sourced from the river banks or borrowpits.

The use of river sand as fine aggregates leads to exploitation of natural resources, lowering of water table, sinking of bridge piers and erosion of river bed [1]. There is a general increase in researches for the use of waste materials in place of natural resources in order to make the concrete industry more sustainable, in terms of protecting the environment and reducing the cost of the concrete. Enormous quantity of Waste Glass (WG) is generated all around the world. In India, $0.7 \%$ of total urban waste generated comprises glass [2].

If fine aggregate is replaced by WG by specific percentage and in specific size range, it will decrease fine aggregate and thereby reduce the ill effects of river dredging, thus making concrete manufacturing industry sustainable [1]. The other method of disposing WG is by dumping in landfills. This procedure is not desirable because WG is non-biodegradable. This quality makes the method environmentally unfriendly. WG is generated from brewery, glass manufacturing industries as well as sites of demolition of old buildings. The quantity of WG generated from the above sources and others not mentioned provides a huge potential for the use of WG in the concrete construction industry.

Guatam et al [3], concluded that the use of WG as fine aggregate replacement in concrete (up to 4\%) did not result in substantial change in strength, but concrete containing up to $30 \%$ fine glass aggregate exhibits higher compressive strength development than normal concrete.

Scivacharam et al [4] observed that compressive strength of concrete made with WG was more than the referral conventional concrete at all replacement levels of cement and natural fine aggregates. Guatam et al, [3] also concluded that WG can effectively be used as fine

* Corresponding author, tel: +234-803-310-6918 
aggregate replacement (up to $40 \%$ ) without substantial change in strength.

Rossomagina et al [5] also concluded that the use of WG as fine aggregate in concrete creates a problem in concrete due to Alkali Silica Reaction (ASR). The reaction between alkalis in Ordinary Portland Cement (OPC) and silica in aggregates forms silica gel. This gel is prone to swelling, because it absorbs water, which results to increase in its volume. Under confinement by cement matrix and aggregate, the swelling of the ASR gel generates hydrostastic pressure. If the reaction continues and internal pressure exceeds the tensile strength of the matrix, cracks will form around the reactive aggregate particle. Adaway and Wang [6] carried out a study on Recycled glass as a partial replacement for fine aggregate in structural concrete- Effects on compressive strength. They concluded that compressive strength increased up to a level of $30 \%$ replacement of fine aggregate with $\mathrm{WG}$, at which point strength developed was $9 \%$ and $6 \%$ higher than control after 7 and 28 days respectively. This led to the conclusion that concrete containing up to $30 \%$ fine glass aggregate exhibits higher compressive strength development than normal concrete. Malik, et al [1] also carried out a study on the use of WG as partial replacement of fine aggregates. They replaced fine aggregates by WG powder at $10 \%, 20 \%, 30 \%$ and $40 \%$ by weight for an M-25 mix. The results also concluded that it was possible to use WG powder as partial replacement of fine aggregates up to $30 \%$ by weight for particle size range $0-1.18 \mathrm{~mm}$.

Scivacharam, et al [4] observed that compressive strength of concrete made with WG was more than the referral conventional concrete at all levels of cement and natural fine aggregate.

Bajad, et al [7] also observed that with increasing replacement of cement with WG powder up to $20 \%$, the highest percentage increase in compressive strength was about 22\% at 20\% replacement level. Topcu and Canbaz [8] concluded that when WG is reused in making concrete, the production cost will go down

When used in construction applications, WG must be crushed and screened to produce an appropriate design gradation. Glass crushing equipment normally used to produce a cullet is similar to rock crushing equipment. Because glass crushing equipment in the glass sector has been primarily designed to reduce the size or density of the cullet for transportation purposes and for use as a glass production feedstock material, The crushing equipment used is typically smaller and uses less energy than conventional aggregate or rock crushing equipment. [9].

Waste glass was used as aggregate for concrete by Johnson [10], Masaki [11] and Park [12]. However the application is limited due to the damaging expansion in the concrete caused by ASR between high-alkali pore water in cement paste and reactive silica in the WG.

Swampy [13] also established that the chemical reaction between the alkali in OPC and silica in aggregates forms silica gel that only causes crack upon expansion but also weakens the concrete and shortens its life. Meyer at al [14] also concluded that another advantage of use of WG in concrete is that special aesthetic effects can be achieved with colour-sorted glass as well as the fact that glass has zero water absorption.

Egesi [9] stated that since plain glass concrete is quite brittle, just like conventional concrete, it is advantageous to reinforce glass concrete products with either randomly distributed short fibres or, in the case of thin sheets or panels, with fibremesh or textile.

This study investigated the performance of concrete with partial replacement of fine aggregate with crushed WG. Concrete properties tested are compressive and flexural strength, setting time and workability, water absorption and light weight character. Previous researchers replaced WG up till 40\% WG content. This study concentrated at WG replacement levels of between $20 \%$ to $60 \%$, with a view to ascertaining the effect of $\mathrm{WG}$ above $5 \%$ replacement level. This is as result of reducing the quantity of sand by $50 \%$ which will consequently reduce the cost of concrete production.

The result of the study will assist in the major challenges arising from increasing construction activities (with resultant production of non-biodegradable materials, like WG) and the associated unbearable burden on the environment as well as rapid depletion of natural resources resulting from sand mining in quest for fine aggregate for the construction industry.

\section{MATERIALS AND METHODOLGY 2.1 MATERIALS \\ 2.1.1 Cement}

The cement used in the study was OPC (Grade 42.5) produced by DANGOTE CEMENT INDUSTRY at Obajana plant in Nigeria. It conformed to BS EN 196-6 [15].

\subsubsection{Fine Aggregate}

Fine aggregate used was obtained from clean river sand at Oyigbo, a suburb of Port Harcourt. The maximum size was $4.75 \mathrm{~mm}$. Impurities were removed and it conformed to the requirements of BS 882 [16].

\subsubsection{Waste Glass}

WG was obtained from disposal dump sites of building reconstruction sites at the Rivers State University of Science \& Technology, Nkpolu, Port Harcourt. The WG primarily originated from pure and clear glass windows. The broken glass were cleaned to remove dirt materials 
and other impurities, then crushed manually and sieved through $1.18 \mathrm{~mm}$ sieve.

\subsubsection{Coarse Aggregate}

Coarse aggregate used was crushed angular and rough textured granite obtained from Ishiagu in Ebonyi State, South Eastern Nigeria. Maximum size was $20 \mathrm{~mm}$.

\subsubsection{Water}

Potable water used was obtained from the Civil Engineering Laboratory of the Rivers State University of Science \& Technology, Port Harcourt.

\subsection{METHODOLOGY}

\subsubsection{Grinding of the Waste Glass into Fine Aggregate}

The WG used in this study was crushed into different sizes to enable ease of grinding. A hand grinding machine was used to manually grind the WG into sizes comparable to fine aggregate size.

\subsubsection{Concrete Mixture}

The mix ratio used for the experiment was 1:2:4 (cement: fine aggregate: coarse aggregate) by weight, the water/cement ratio was 0.6. The fine aggregate was replaced with WG at $15 \%, 25 \%, 35 \%, 45 \%$ and $50 \%$ partial replacement for sand. For each replacement level, 3 specimens were prepared for the compressive strength, while 3 specimens were prepared for the flexural strength. The average of these number of specimens were obtained and used for analysis. All concrete cube specimens were cured in water tank for 7 and 28 days respectively. Table 1 shows the concrete mix Design Summary for the Compressive Strength test while, Table 2 is the mix design for the Flexural Strength test.

\subsubsection{Sieve Analysis}

Sieve Analysis was carried out to determine the particle size distribution. The sieve analysis was carried out in accordance with BS 410 [17].

\subsubsection{Chemical Analysis of Waste Glass Particles}

Chemical Analysis of dried samples of the WG was carried out in the Chemical/Petroleum Laboratory of the Rivers State University of Science Technology, Nkpolu, Port Harcourt in accordance with APHA [18].

\subsubsection{Specific Gravity}

Specific Gravity test was performed in accordance with BS 812-2 [19].

\subsubsection{Bulk Density and Unit Weight}

Bulk Density and Unit Weight tests were performed in accordance with BS 812-2 [19] and BS 1377-4 [20].

\subsubsection{Workability}

Slump test was carried out in accordance with BS 123502 [21].

\subsubsection{Compressive Strength}

Compressive strength test was carried out in accordance with BS 1881-116 [22] and BS 1881-108 [23]. For each replacement level, 3 cubes were prepared, cured and crushed and the average value of the 3 results was used. Mix Design for the compressive strength Test is shown in Table 1.

\subsubsection{Flexural Strength}

Flexural strength tests were carried out in accordance with BS 12390-5 [24]. 2 test specimens were prepared for each replacement level and the average result was used. Mix Design for the flexural strength test is shown in Table 2 .

\subsubsection{Setting Time}

Initial and Final setting times were obtained in accordance with BS 196-3 [25].

\section{RESULTS AND DISCUSSION}

\subsection{Chemical Composition of Waste Glass}

Table 3 shows chemical composition of the WG. Silicon Oxide is the highest constituent of the glass, the second next highest constituent is Lead Oxide.

Table 1: Concrete Mixes Design Summary for Compressive Strength with $1.44 \mathrm{~kg}$ of Water, $2.40 \mathrm{~kg}$ of Cement and $9.50 \mathrm{~kg}$ of Coarse aggregate

\begin{tabular}{ccc}
\hline $\begin{array}{c}\text { Glass Replacement } \\
(\%)\end{array}$ & $\begin{array}{c}\text { Natural fine } \\
\text { Aggregate }(\mathrm{Kg})\end{array}$ & $\begin{array}{c}\text { Glass fine } \\
\text { Aggregate }(\mathrm{Kg})\end{array}$ \\
\hline 0 & 4.70 & 0.00 \\
15 & 3.99 & 0.71 \\
25 & 3.50 & 1.20 \\
35 & 3.00 & 1.66 \\
45 & 2.60 & 2.12 \\
50 & 2.35 & 2.35 \\
\hline
\end{tabular}

Table 2: Concrete Mix Design Summary for Flexural Strength for $2.04 \mathrm{~kg}$ of Water, $3.40 \mathrm{Kg}$ of Cement and $13.7 \mathrm{~kg}$ of Coarse aggregate

\begin{tabular}{ccc}
\multicolumn{3}{c}{ aggregate } \\
\hline $\begin{array}{c}\text { Glass Replacement } \\
(\%)\end{array}$ & $\begin{array}{c}\text { Natural fine } \\
\text { Aggregate }(\mathrm{Kg})\end{array}$ & $\begin{array}{c}\text { Glass fine } \\
\text { Aggregate }(\mathrm{Kg})\end{array}$ \\
\hline 0 & 6.80 & 0.00 \\
15 & 5.78 & 1.02 \\
25 & 5.10 & 1.70 \\
35 & 4.42 & 2.38 \\
45 & 3.74 & 3.06 \\
50 & 3.40 & 3.40
\end{tabular}


Table 3: Chemical Composition of Glass

\begin{tabular}{rlcrl}
\hline S/N & Parameter (\%) & Test method & Result & Standard \\
\hline 1 & Silicon Oxide & APHA 3114B [18] & 52.89 & $45-90$ \\
2 & Magnesium Oxide & $"$ & 3.75 & $2.5-7.50$ \\
3 & Sodium Oxide & $"$ & 11.60 & $14.20 \mathrm{max}$ \\
4 & Aluminium Oxide & $"$ & 8.14 & $0.50-16.00$ \\
5 & Potassium Oxide & $"$ & 11.62 & $12.0 \mathrm{max}$ \\
6 & ferric Oxide & $"$ & 0.08 & 0.10 \\
7 & Calcium Oxide & $"$ & 6.69 & $10.00 \mathrm{max}$ \\
8 & Boric Oxide & $"$ & 7.17 & $4.00-12.00$ \\
9 & Zinc Oxide & $"$ & 1.33 & $1.50 \mathrm{max}$ \\
10 & Lead Oxide & $"$ & 22.30 & $25.0 \mathrm{max}$ \\
\hline
\end{tabular}

\subsection{Particle Size Distribution}

Table 4 shows the gradation of both sand and WG aggregates. The WG was further subjected to a mechanical sieving process, with fractions in excess of $1.18 \mathrm{~mm}$ being discarded in order to avoid ASR [6]. The sand belongs to (A-1-b) type in the ASSHTO Soil Classification System.

\subsection{Physical Properties of Aggregates}

Table 5 shows the values of the physical properties of the various aggregates. They correspond to known values from previous works.
Table 4: Gradation of Sand and Waste Glass aggregate

\begin{tabular}{ccc}
\hline \multirow{2}{*}{ Sieve Size $(\mathrm{mm})$} & \multicolumn{2}{c}{ Accumulated \% Passing } \\
\cline { 2 - 3 } & Waste Glass Aggregate & Sand Aggregate \\
\hline 4.750 & 0 & 98.07 \\
2.360 & 0 & 93.40 \\
2.000 & 0 & 87.40 \\
1.180 & 0 & 78.97 \\
0.850 & 93.80 & 68.97 \\
0.600 & 75.80 & 58.47 \\
0.425 & 53.97 & 44.47 \\
0.300 & 31.24 & 21.47 \\
0.150 & 7.01 & 0.34 \\
0.075 & 1.34 & 0.01 \\
\hline
\end{tabular}

Table 5: Physical Properties of Aggregates

\begin{tabular}{lccc}
\hline \multicolumn{1}{c}{ Property } & Fine & Glass & Coarse \\
\hline Specific gravity & 2.82 & 2.52 & 2.76 \\
Bulk density $(\mathrm{Kg} / \mathrm{m} 3)$ & 1830.00 & 1540 & 1310 \\
Unit Weight $\left(\mathrm{Kg} / \mathrm{m}^{3}\right)$ & 16.80 & 15.11 & 12.85 \\
Water absorption $(\%)$ & 0.40 & 0.35 & 3.00 \\
\hline
\end{tabular}

\subsection{Workability}

The slump test result is shown in Figure 3. It was observed that the workability of concrete made with WG as fine aggregate increased as the content of WG increased. The workability started to decrease at $35 \%$ WG replacement level.

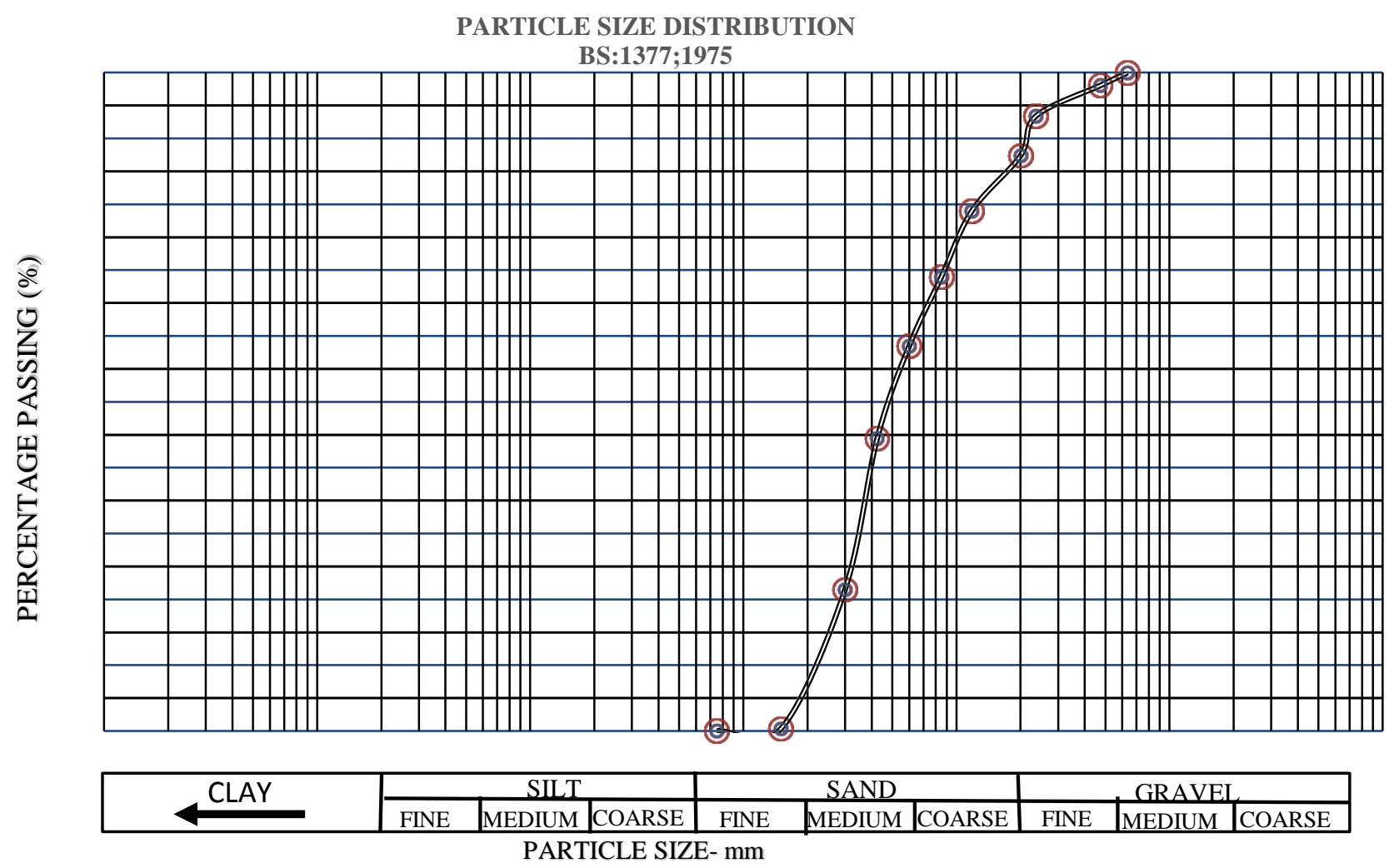

Figure 1: Particle Size Distribution Curve for Sand 
PARTICLE SIZE DISTRIBUTION

BS: $1377 ; 1975$

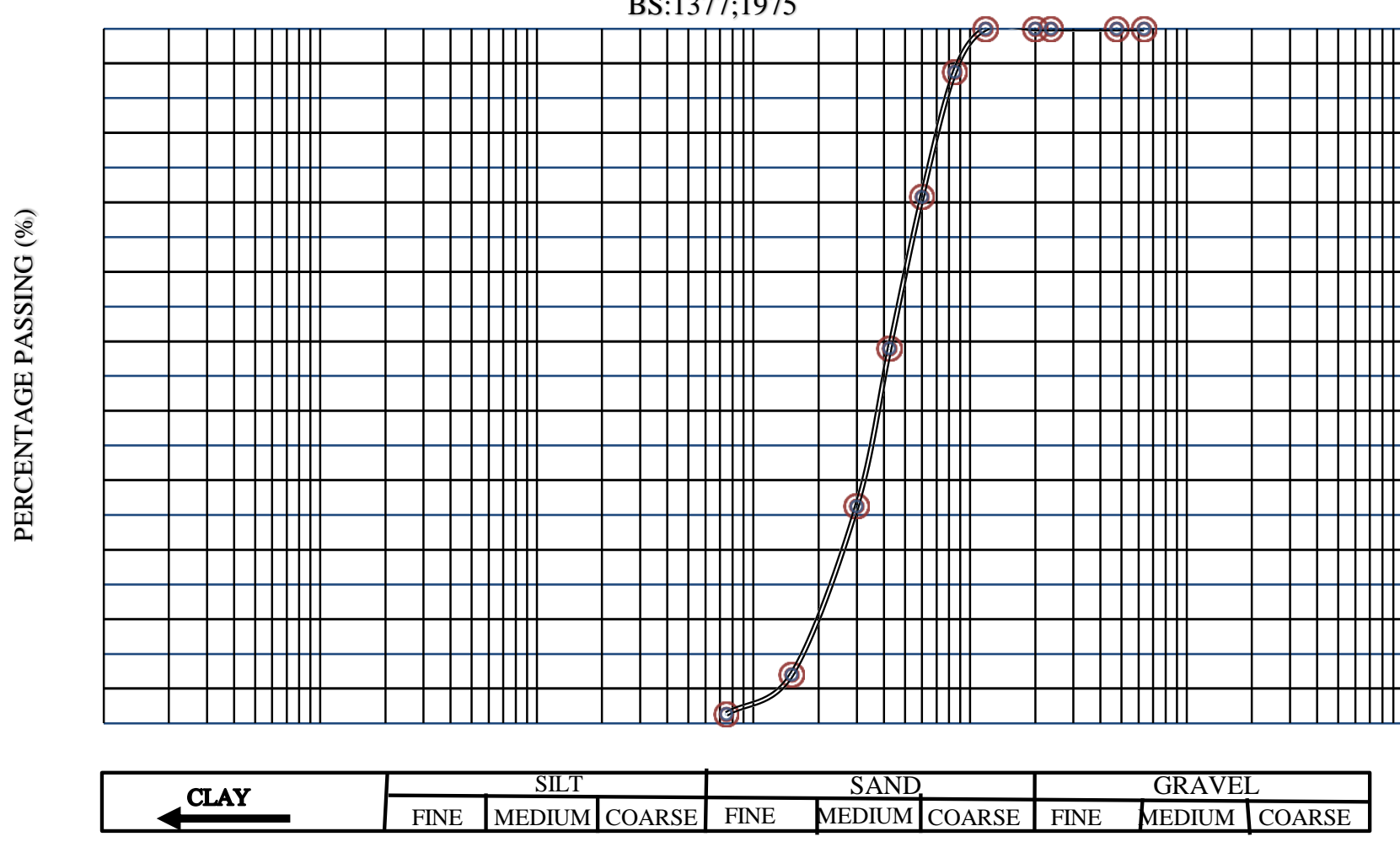

PARTICLE SIZE- $\mathrm{mm}$

Figure 2: Particle Size Distribution Curve for WG fine particles

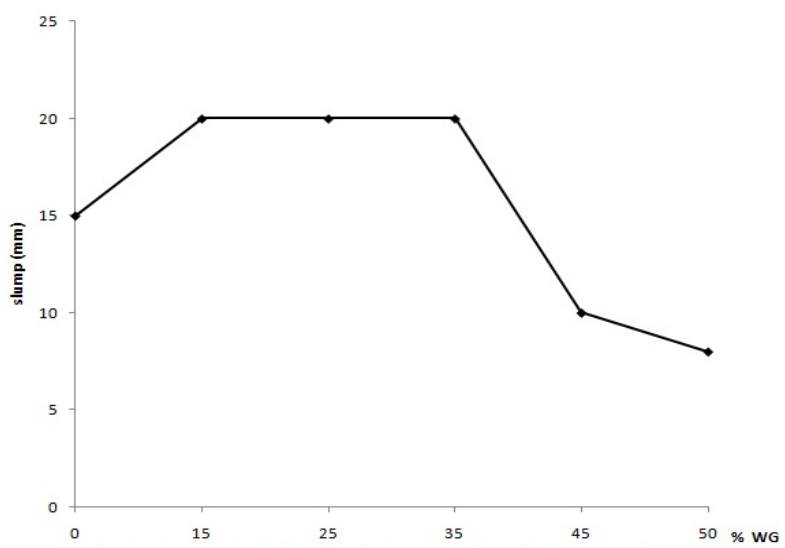

Figure 3: Variation Slump with Percentage of $W G$ Replacement

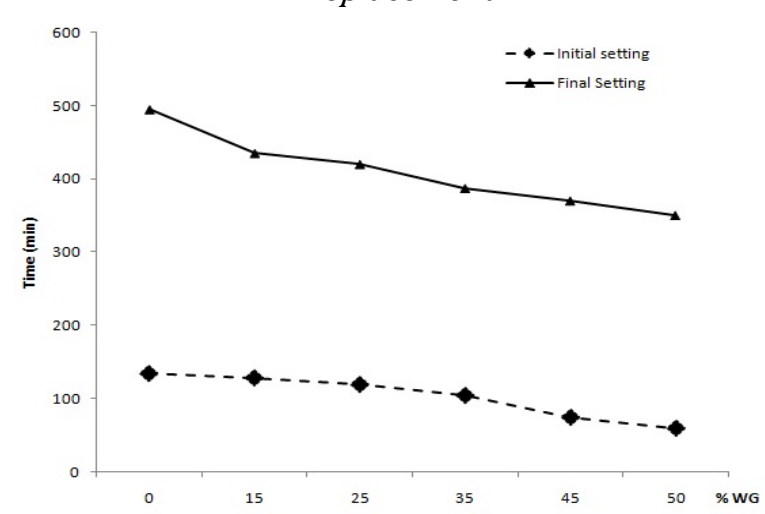

Figure 4: Variation of Setting Time with Percentage of WG Replacement
This result is consistent with Taha and Nounu [26], who concluded that the addition of WG to the concrete mix was found to decrease concrete slump, yet workability was still deemed sufficiently adequate without the need for admixtures for replacement levels up to $50 \%$. In higher mix proportions, the addition of WG was found to negatively affect the properties of fresh concrete, resulting in severe segregation and bleeding. Scivaracham [4] also observed an increase in workability of concrete made using $W G$ as fine aggregate replacement up to $40 \%$ and thereafter reduction in workability was observed.

\subsection{Setting Time}

Figure 4 shows variation of the initial and final setting time with various replacement levels of fine aggregate with WG. Both the initial and final setting time decreased as the percentage of WG was increased. The decrease in the setting time compared to that of the control may be attributed to the angular nature of the WG aggregate, which has greater surface area than natural rounded sand particles. The angular nature of the glass, also tend to facilitate increased bonding with cement paste.

\subsection{Compressive Strength}

The variation of the compressive strength at 7 and 28 days with the various replacement levels of fine aggregates with WG is shown in Figure5. For the 7 days 
compressive strength, it can be noticed that there is an increase in compressive strength as the WG content in the concrete was increased, up to $15 \%$ replacement level, when a maximum compressive strength of $23.33 \mathrm{~N} / \mathrm{mm}^{2}$ was attained increase above the control value. The 28 days compressive strength test result is a mirror image of the 7 days compressive strength test. The compressive strength at 28 days increased as the WG content was increased up to $15 \%$ WG content. The maximum strength developed at the $15 \%$ replacement level is $32.67 \mathrm{~N} / \mathrm{mm}^{2}$ which is $7 \%$ higher than the compressive strength 30.67 $\mathrm{N} / \mathrm{mm}^{2}$ of the control mix. After the $15 \%$ replacement level, the value of the compressive strength started to decrease as the WG content was increased.

These findings are supported by the result of Tuncan et al [27], who established that the compressive strength of the concrete after 7 days of curing was found to increase with the addition of WG.

Adaway and Wang [6] attributed this scenario to the angular nature of the glass aggregate, which has a greater surface area than the naturally rounded sand particles. The increased surface area allows for greater bonding with the cement paste, resulting in a stronger concrete Adaway and Wang [6]. Replacement levels above $15 \%$ adversely affected the development of compressive strength. Furthermore, the result of this study concurs with similar findings which were obtained by Malik et al [1], who found that compressive strength reduced by $8 \%$ at a WG replacement of $40 \%$ when adopting similar glass particle distribution as to that adopted in this study.

Adaway and Wang [6], also concluded that whilst previous studies have implied that this tendency is as a result of reduced adhesion between the glass particles and cement paste (reference), the results from their study suggest that the angular nature of the glass particles may further contribute to the witnessed reduction in strength. They suggested that where glass aggregate is present in higher proportion, there is insufficient cement paste, available within the mix to facilitate bonding with all the particles, resulting in the formation of microscopic voids which adversely affect concrete strength. It was also observed that on replacing fine aggregate by $25 \% \mathrm{WG}$, there was a decrease in compressive strength by $14.73 \%$ at 7 days and $23.50 \%$ at 28 days.

\subsection{Flexural Strength}

Figure 6 shows that the flexural strength remained constant at values of $5.7 \mathrm{~N} / \mathrm{mm}^{2}$ and $7.6 \mathrm{~N} / \mathrm{mm}^{2}$ after 7 and 28 days respectively at $15 \%$, thereafter there were fluctuations in the values of the flexural strength. There was a decrease of $25 \%$ and $46 \%$ at $25 \%$ WG replacement level after 7 and 28 days respectively. Increase of 33\% and $37.5 \%$ in flexural strength was recorded at 35\% WG replacement level at 7 and 28 days respectively. It is recommended that further study of the effect of $W G$ on flexural strength at these WG replacement levels be carried out to re-confirm these values.

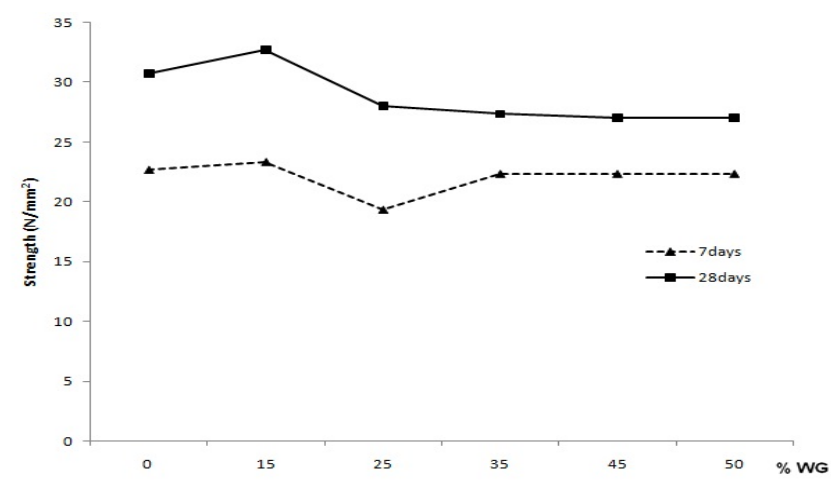

Figure 5: Variation of Compressive Strength with Percentage of WG Replacement

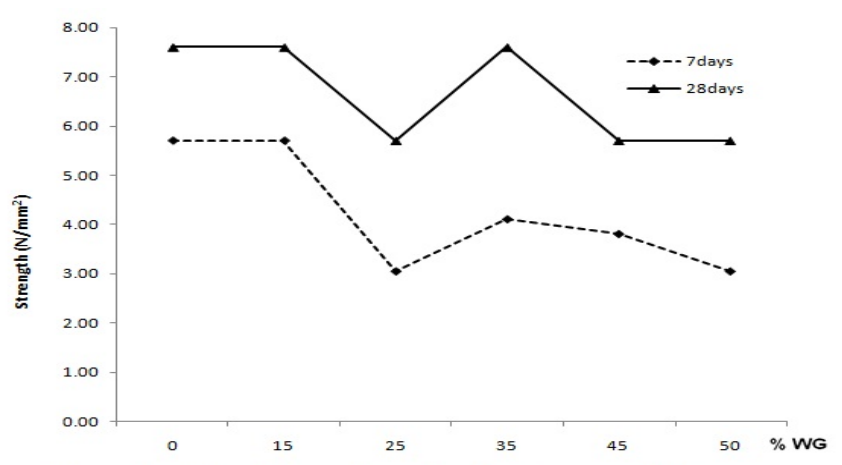

Figure 6: Variation of Flexural Strength with Percentage of WG Replacement

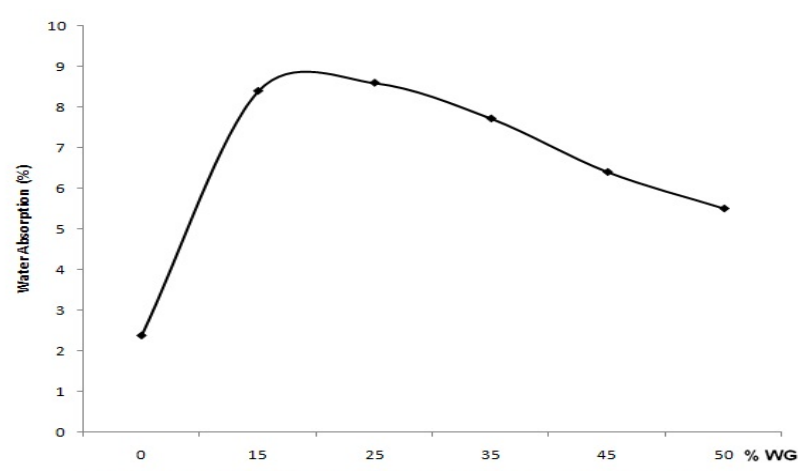

Figure 7: Variation of water Absorption with Percentage of WG Replacement

\subsection{Water Absorption}

Figure 7 shows variation of the water absorption with replacement levels of WG. The water absorption decreases as the WG content increases in the concrete. The lowest water absorption was recorded at $50 \% \mathrm{WG}$ replacement level. The reason is that glass has zero water absorption property, as such water absorption of the concrete decreased as the WG content increased. 


\section{CONCLUSION}

The compressive strength of the concrete at 7 and 28 days increased as the WG replacement level increased to maximum values at $15 \%$ replacement. This means that optimum replacement of fine aggregate with WG occurred at $15 \%$ replacement level. The flexural strength of concrete fluctuated as percentage replacement of WG increased. This area is recommended for further study. Above 15\% WG replacement level, WG was fine aggregate, negatively impact on the development of compressive strength of concrete.

The initial and final setting times decreased as the percentage of WG increased up to $15 \%$ replacement level. This confirms that fine WG aggregate could act as retarder in concrete up to $15 \%$ replacement level.

The water absorption decreased as the percentage of WG increased.

The results of the study generally demonstrated that partial replacement of fine aggregate with WG is economical. Since the quantity of the expensive sand (fine aggregate) can be reduced up to $15 \%$ replacement level and considering the fact that WG is usually disposed off and can be obtained at little or no cost in comparison with sand, cost of concrete production can be relatively reduced using this waste.

The use of WG in concrete production will result in sustainable environmental protection since the disposal of WG (non-biodegradable) is usually a problem.

\section{REFERENCES}

[1] Malik, MIgbal, Bashir, M., Ahmad, S., Tarid, T., and Chowdhary, U."Study of Concrete Involving use of Waste Glass as Partial Replacement of Fine Aggregates". IOSR HJournal of Engineering India, July pp. 8-13. 2013.

[2] Asoka, P., Mohini, S. and Shyan, R. A." Solid Waste Generation in India and their Recycling Potential in BuildingMaterials". Regional Research Institute (CSTR) and IIT Bombay, India, 2007.

[3] Guatam, S. P., Srivastava, V. and Agarwal, V. C." Use of Glass wastes as fine aggregate in Concrete". J. Acad. Industries Res. Vol (16). 2012.

[4] Scivacharam, S., Vikas, S., Agarwal, V. C. "Glass Waste in Concrete: Effect on Workability and Compressive Strength". International Journal of Innovative Research in Science, Engineering and Technology, Vol. 4, No. 9, pp 8142-8150. 2015.

[5] Rossomagina, A. S., Saulin, D. V. and Puzano, I.S. Prevention of Alkali-Silica Reaction in Glass Aggregate Concrete. Perm State Technical University, Rusia, pp.2. 2015.

[6] Adaway, M. and Wang, Y."Recycled glass as a partial replacement for fine aggregate in structural concrete - Effects on compressive Strength".
Electronic Journal of Structural Engineering, Vol. 14, No. 1, pp.116-122. 2015.

[7] Bajad, M. N., Modhera, C. D. and Desai, A. K." Effect of Glass on Strength of Concrete Subjected to Sulphate Attack". International Journal of Civil Envgineering Research and Development (IJCERD),ISSN, 2228-9428, Vol. 1, 2011.

[8] Topcu I. B. and Canbaz, M. " Properties of Concrete containing waste glass". Cement and concrete Research, Vol. 34, , pp.267-274. 2004.

[9] Egosi,N."Mixed Broken Glass Processing Solutions".Proceedings American Society of Civil Engineers, National Convention, New York, N. Y. September, pp.14.1992.

[10] Johnson, C. D. "Waste Glass as coarse aggregate for concrete". J. Testing Evaluation, Vol. 2, pp. 344-350. 1998.

[11] Masaki, O. "Study on hydration hardening character of glass powder and basic physical properties of waste glass as construction material". Asahi Ceramic Foundation Annual Technical Report, pp. 143-147. 2000.

[12] Park, S. B. "Development of recycling and treatmnt technologies for construction waste". Ministry of Construction and Transportation, Seoul, Tech Report, pp.134-137. 2000.

[13] Swampy, R. N. "The alkali-silica reaction in concrete". $2^{\text {nd }}$ Edition, USATaylor and Francis, pp. 335, 1992.

[14] Meyer, C., Egosi, N., and Andela, C. "Concrete with waste glass as aggregate", Proceedings of the International Symposium. Concrete Technology Unit of ASCE and University of Dundee, 19-20, March 2001.

[15] BS EN196-6; - Methods of Testing Cement. Determination of finennes, British Standards Institute London, United Kingdom. 2010.

[16] BS 882; - Specifcation for Aggregates from natural sources for Concrete, British Standards Institute. London, United Kingdom 1992.

[17] BS410;- Specifcation for test sieves.British Standards Institute London, United Kingdom 1996.

[18] APHA Method; American Punlic Health AssociationStandard Method for the Examination of Water and Wastewater, 22 ${ }^{\text {nd }}$ Edition, Washington DC, USA, 2012.

[19] BS 812-2; - Testing Aggregates. Methods for determination of density. British Standards Institute London, United Kingdom. 1995.

[20] BS 1377- 4; - Methods of Testing of Soils for Engineering. British Standards Institute. London United Kingdom. 1990. 
[21] BS 12350-2;- Testing of Concrete: Slump Test, British Standards Institute. London, United Kingdom, 2009.

[22] BS 1881-116; - Testing Concrete. Method for determination of compressive Strength of concrete cubes. British Standards Institute. London, United Kingdom. 1983.

[23] BS 1881-108; - Method of making test cubes for fresh concrete. BS British Standards Institute. London, United Kingdom. 1983.

[24] BS 12390-5; - Testing Hardened Concrete. Flexural Strength of test Specimens. BS British Standards Institute .London, United Kingdom 2005.
[25] BS196-3;2005 +A1; 2008 - Methods of Testing Cement. Determination of setting times and Soundness. BS British Standards Institute .London, United Kingdom. 2008.

[26] Taha, B. and Nounu, G. "Properties of Concrete contains mixed colour waste recycled glass as sand and cement replacement". Construction Build. Mater, Vol. 22, , pp. 713-720. 2008.

[27] Tuncan, M., Karasu, B. and Yalcin, M. "The suitability for using glass and fly ash in Portland Cement Concrete". Proceedings of the International Offshore and Polar Enginering Conference, pp. 146152, 2001. 